\title{
Comparative Studies of Carbon Materials \\ Synthesized From Waste as Catalysts for Ozonation of Real Textile Wastewater
}

\section{Vijay A. Juwar}

VNIT: Visvesvaraya National Institute of Technology

\section{AJIT RATHOD ( $\square$ ajitprathod@gmail.com )}

Visvesvaraya National Institute of Technology https://orcid.org/0000-0001-6060-1404

Shyam M. Kodape

Visvesvaraya Regional College of Engineering: Visvesvaraya National Institute of Technology

\section{Research Article}

Keywords: Activated carbon, Multiwalled carbon nanotubes, Ozonation, $\cdot \mathrm{OH}$ exposure, Specific ozone dose

Posted Date: October 1st, 2021

DOI: https://doi.org/10.21203/rs.3.rs-881195/v1

License: (9) This work is licensed under a Creative Commons Attribution 4.0 International License. Read Full License 


\title{
Comparative Studies of Carbon Materials Synthesized from Waste as Catalysts for Ozonation of Real Textile Wastewater
}

\author{
Vijay A. Juwar, Ajit P. Rathod*, Shyam M. Kodape \\ Chemical Engineering Department, Visvesaraya National Institute of Technology, Nagpur- \\ India 440010 \\ Email:ajitprathod@gmail.com \\ * Corresponding Author
}

\begin{abstract}
In the present work, evaluation of two catalysts, Activated carbon (AC) synthesized from agricultural waste and Multiwalled carbon nanotubes (MWCNT) synthesized from plastic waste, were done for the ozonation of real textile wastewater using para- chloro benzoic acid ( $p$-CBA) as a probe compound. The effect of $\mathrm{pH}$ and catalyst dose were studied in terms of - $\mathrm{OH}$ exposure, Rct, rate of $p$-CBA degradation and ozone degradation. The rate constant for the reaction of organic matter with hydroxyl radicals was determined using competition kinetics. The threshold ozone dose for real textile wastewater was found to be $0.51 \mathrm{gm} / \mathrm{gm}$ of TOC. With an increase in specific ozone dose, the rate of $p$-CBA degradation was found to be increasing and has shown a positive effect on $\bullet \mathrm{OH}$ exposure and Rct. The increasing $\mathrm{pH}$ had shown a positive effect on the rate of degradation and decomposition of $p$-CBA and ozone respectively in the case of AC catalyzed ozonation. A similar trend was observed in the case of MWCNTs catalyzed ozonation. A positive effect of $\mathrm{pH}$ was observed on $\bullet \mathrm{OH}$ exposure and Rct, in AC as well as MWCNTs catalyzed ozonation. The effect of catalyst loading has shown significant enhancement in $p$-CBA degradation, ozone decomposition, $\bullet \mathrm{OH}$ exposure and Rct in both AC as well as MWCNTs catalyzed ozonation. However, MWCNTs have proved better than $\mathrm{AC}$ as a catalyst for ozonation in studied experimental parameters.
\end{abstract}

Key words: Activated carbon, Multiwalled carbon nanotubes, Ozonation, $\bullet \mathrm{OH}$ exposure, Specific ozone dose

\section{Introduction}

Ozone $\left(\mathrm{O}_{3}\right)$, a powerful oxidant capable of reacting with organic and inorganic compounds, has been widely applied for water and wastewater treatment (Bielski et al. 1985, Hoigné, 1998). The transformation of organic pollutants with ozone occurs via direct reaction with molecular ozone or with hydroxyl radicals $(\bullet \mathrm{OH})$ resulting from ozone decomposition in water [von Gunten, 2003]. Molecular ozone has a limitation of selectively reacting with organic pollutants having single bonds and aromatics substituted with electron withdrawing groups (Langlais et al. 1991). To overcome the limitation of molecular ozone, advanced 
oxidation processes (AOPs) based enhanced formation of $\bullet \mathrm{OH}$ radicals have been developed (Glaze et. al.1987). Ozone goes through chain reactions and forms several secondary oxidants, prominently, hydroxyl radical, a strongest and most non selective oxidant in water. It readily attacks most of the organic pollutants and converts them into less complex and less harmful intermediate products (Langlais et. al. 1991). In recent times, catalytic ozonation has proven to be an effective technique for aqueous pollutant degradation (Kasprzyk-Hordern et. al.2003). In 1970, heterogeneous catalytic ozonation was likely presented (Chen et. al.1977). Heterogeneous ozonation offers certain favourable circumstances over homogeneous ozonation, for example, cleaner process, independent of additional stoichiometric reagents (Fan et. al. 2014.). Carbon materials, for example, activated or synthetic carbons, have been considered for catalytic ozonation since the 1990s (Jans and Hoigné 1998). Because of supportive properties of carbon materials like ready at a lower price, availability of several pores structures and no metal leaching from synthetic carbon, these materials turned into an attractive alternative for catalytic ozonation. (Fan et.al.2014). The integrated utilization of ozone and activated carbon (AC) has been widely researched by Jans and Hoine (Jans and Hoigné 1998) to eliminate toxic and low biodegradable compounds from water. The process amalgamates the calibre of high oxidative strength of ozone and transformation of ozone into hydroxyl radicals by AC, which can degrade aqueous organic compounds. Numerous aqueous compounds have been successfully degraded by AC catalyzed ozonation. ( Fontanier et al.2005, Rodrguez et al. 2008). Nanostructured carbon materials, for example, nanotubes and nanofibres, have diverse surface properties when contrasted with particulate carbon materials, for example, activated carbon. Carbon nanotubes display a great capacity to adsorb compounds from water. (Chiang and $\mathrm{Wu}, 2010$, Yu et. al.2011) The major limitation of AC in liquid media is the diffusion of solute in its micro pores may be very slow; it can be even more disastrous in aqueous media due to the hydrophobic nature of the carbon surface. In contrast, the mesoporus nature of nanocarbon material facilitates diffusion through pore network. (Job et.al. 2006). In literature, there are a few studies reported on multiwalled carbon nanotube (MWCNT) as a very promising material for catalytic ozonation. MWCNT of commercial grade was used in catalytic ozonation of oxalic acid, (Liu et.al.2009) SMX, (Goncalves et al.2012) bezafibrate (Goncalves et. al.2013) and attrazine (Fan et. al. 2014) successfully.

The hydroxyl radical concentration is a crucial parameter for determination of the reaction rate. Due to the low concentration of hydroxyl radicals, its quantitative measurement is rather difficult. On the contrary, ozone concentration can be measured by several methods. (Langlais et al. 1999) For the prediction of hydroxyl radical concentration, a few computer models have been developed.(Chelkowska et al. 1992) An indirect method, using para chlorobenzoic acid (p-CBA), was developed by Elovitz and von Gunten ( Elovitz and Von Gunten 1999). Up to recent times, several studies have been conducted to evaluate the effectiveness of AOPs like $\mathrm{O}_{3}+\mathrm{UV}, \mathrm{O}_{3} / \mathrm{H}_{2} \mathrm{O}_{2}, \mathrm{O}_{3} / \mathrm{H}_{2} \mathrm{O}_{2} / \mathrm{UV}$ in terms of hydroxyl radical generation. Most of the studies used municipal wastewater. (Wert et al. 2009, Lee et al. 2013, Lee et al. 2014, Guo et al.2018, Liu et al. 2019, Liu et al. 2020), hospital wastewater (Lee et. al. 2014) and industrial wastewater (Liu et. al. 2020). Very few studies have evaluated catalytic performance for hydroxyl radical generation. (Ahn et al.2017, Guo et al.2018, Guo 
et al.2019, Guo et al.2020). There are no studies reported on evaluation of catalytic performance for hydroxyl radical generation in industrial wastewater. In this study, the textile industry wastewater was used to evaluate the effectiveness of activated carbon and multiwalled carbon nanotubes for hydroxyl radical generation. The effect of different parameters such as catalyst, ozone dose, and $\mathrm{pH}$ were studied. The total scavenging rate of hydroxyl radicals was evaluated. This study is an attempt to portray a real time picture of hydroxyl radial generation in industrial wastewater with activated carbon and multiwalled carbon nanotubes.

\section{Materials and Method}

\subsection{Water Sampling}

A wastewater effluent sample was collected from the equalization tank of the textile industry near Nagpur district, Maharashtra, India. The sample was used without any dilution or additional filtration prior to ozonation experiments. The sample was kept in a refrigerator at $4^{0} \mathrm{C}$ before further usage.

\section{Table 1: Characterization of textile wastewater}

\subsection{Analytical methods}

The ozone concentrations in the stock solution were determined by the indigo method. Concentrations of hydroxyl radicals probe compound $p$-chlorobenzoic acid ( $p$-CBA) were determined by high performance liquid chromatography (HPLC) with reverse phase column and UV-Vis wavelength detector.

\subsection{Experimental set-up}

A fresh ozone stock solution (50-60 $\mathrm{mgL}^{-1}$ ) was prepared by bubbling ozone gas into a one litre gas washing bottle which was ice cooled and contained demineralised water. The ozone gas was generated using ozone generator (Faraday Ozone, India). The catalyst solutions were

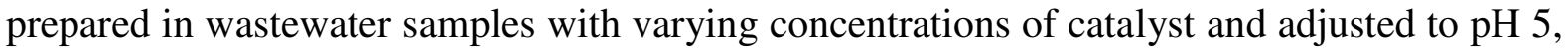
7, 8 and 9 using $0.1 \mathrm{~N} \mathrm{H}_{2} \mathrm{SO}_{4}$ and $\mathrm{NaOH}$. The desired ozone dose was achieved by varying ratios of sample and stock solution. The initial concentration of $p$-CBA was $1 \mu \mathrm{M}$.

\subsection{Preparation of Activated carbon}

Cajanus cajan husk was obtained from the pulse processing industry in Nagpur. It was washed with water and double distilled water to remove dust particles. It was then dried to remove moisture content in a hot air oven at about $110^{\circ} \mathrm{C}$ for $8 \mathrm{hrs}$. It was crushed and sieved so as to get particles in the size range of 50 to $100 \mu \mathrm{m}$. Then it was carbonized in a muffle furnace at about $450^{\circ} \mathrm{C}$ for 4 hours. It was treated with concentrated hydrochloric acid to remove ash from carbon. The $\mathrm{pH}$ was brought to 7 by repeated washing of carbon using distilled water. Then it was dried in a hot air oven at $110^{\circ} \mathrm{C}$ for $8 \mathrm{hrs}$ to remove the moisture content. It was activated by treating it with conc. sulfuric acid at the ration of 1:10 (wt.of 
carbon/volume of sulfuric acid) for $10 \mathrm{hrs}$. The mixture was filtered and the filtrate was repeatedly washed with double distilled water to bring the $\mathrm{pH}$ to 7 . To remove the moisture content, it was dried in a hot air oven at $110^{\circ} \mathrm{C}$ for $4 \mathrm{hrs}$. Then it was heated in a muffle furnace at $800^{\circ} \mathrm{C}$ for 2 hours for activation. The scanning electron microscopy image of activated carbon is shown in fig. 1 and the XRD patterns of AC are as shown in fig. 2. The SEM image of activated carbon (AC) shows a plate-like structure with an average thickness of 1-2 micrometers. The SEM image indicates no specific shape and size of materials, i.e. uneven shape and size distribution. The diameters of MWCNTs range from 15.5-22.5 nm in SEM images. It is difficult to determine the \% purity of MWCNTs from SEM image. The catalyst appears at the tip of the MWCNTs. The HRTEM analysis shows well aligned graphene walls of around 25-35 with 2-3 nm inner diameters. The XRD scan of AC corresponds to its SEM image showing a high amount of noise which resembles an uneven size and shape.The XRD peak correspounds with carbon peak $2 \theta=26.26$ (At (002) plane). The smooth curve in the XRD pattern indicates high amorphous material. The XRD patterns show a well resolved peak similar to AC for graphite at $2 \theta=26.62$ and indicates the absence of amorphous carbon and asserts the formation of MWCNTs.

Fourier transform infrared spectroscopy (FTIR) and Brunauer-Emmet-Teller (BET) for surface morphology are available in the literature. (Bhusari et al.2020)

\section{Figure 1: SEM image of Activated carbon}

\section{Figure: 2 XRD Pattern for Activated Carbon}

\subsection{Preparation of Multiwalled carbon nanotubes}

The MWCNTs were synthesized from polypropylene (PP) bottles used for packing chemicals. The small pieces of PP at an approximate size of $1 \mathrm{~cm} \times 1 \mathrm{~cm}$ were made from cleaned bottles of PP. The mixture of shredded PP and the desired amount of $\mathrm{Ni} / \mathrm{Mo} / \mathrm{MgO}$ catalyst was taken into a silica crucible covered with a lid and kept in an electrically heated muffle furnace at the desired temperature. The red hot crucible was removed from the furnace after $10 \mathrm{~min}$. and was cooled to room temperature. To remove the catalyst particles, the synthesized MWCNTs were ultrasonicated with concentrated hydrochloric acid for 30 mins. By oxidising MWCNTs in a muffle furnace at $400^{\circ} \mathrm{C}$ for $2 \mathrm{hrs}$, the amorphous carbon in the product was removed. The XRD patterns show a well resolved peak for graphite at $2 \theta=$ 26.62 which indicates absence of amorphous carbon and asserts formation of MWCNTs. The diameters of MWCNTs range from 15.5-22.5 nm in SEM images. It is difficult to determine the purity of MWCNTs from SEM images. The catalyst appears at the tip of the MWCNTs. The HRTEM analysis shows well aligned graphene walls of around 25-35 with 2-3 nm inner diameters. The preparation and characterization of multiwalled carbon nanotubes is discussed in the literature (Bajad et.al.2015). The BET surface area of MWCNTs is 28.5 Sq.m./gm.

\section{Results and Discussions}




\subsection{0zone and $\bullet O H$ Exposure}

The ozone exposures were calculated from the area under the ozone decay curves. (von Gunten and Hoigne 1994). The Indigo method was used to determine the residual ozone. (Bader and Hoigne, 1981). pCBA (para-chlorobenzoic acid) is usually used as a probe compound due to its low apparent second order reaction rate constant with ozone $\left(<0.1 \mathrm{M}^{-1}\right.$ $\left.\mathrm{s}^{-1}\right)$ and its high reaction rate with ${ }^{\circ} \mathrm{OH}\left(5.0 \times 109 \mathrm{M}^{-1} \mathrm{~s}-1\right)($ von Sonntag and von Gunten 2012, Rosenfeldt and Linden 2007) The ${ }^{\circ} \mathrm{OH}$ exposure is calculated by equation 1 :

$$
\int \cdot \mathrm{OH} d t=\frac{\ln [p C B A]_{0}-\ln [p C B A]}{k \cdot \mathrm{oH}, \mathrm{pCBA}}
$$

The Rct represents a dimensionless number comparing the potential for oxidation by $\bullet \mathrm{OH}$ to the potential for oxidation by $\mathrm{O}_{3}$. The Rct value is not just the ratio of $\bullet \mathrm{OH}$ exposure to $\mathrm{O}_{3}$ exposure as shown in equation 2 , but it is the ratio of total initiation capacity to total inhibition capacity in a system.(Yong and Lin 2012).

$\mathrm{Rct}=\frac{\int[\cdot \mathrm{OH}] \mathrm{dt}}{\int[\mathrm{O} 3] d t}$

At different reaction times, the measured concentration in the experimental solutions was calculated. Ozone exposures at specific ozone doses are shown in fig.3A.With increasing specific ozone dose, the ozone exposure increases during ozonation. The ozone exposure was $(0.625-3.3)^{*} 10^{\wedge}-3 \mathrm{M} \mathrm{s}$ for the textile wastewater. At a lower specific ozone dose of $0.3 \mathrm{gm}$ $\mathrm{O}_{3} / \mathrm{gm} \mathrm{TOC}$, it was not possible to measure ozone exposure. It seemed that ozone was rapidly decomposed during instantaneous ozone demand (IOD) or consumed by water matrix. At different specific ozone doses, the ozone decay was completed within $\leq 15 \mathrm{~min}$.

It can be seen from fig. $3 \mathrm{~A}$, that $\bullet \mathrm{OH}$ Exposure increases with an increase in specific ozone dose. It shows a linear relation of ozone exposure and specific ozone dose $\left(R^{2}=0.94\right)$ which is agreement with (Audenaert et.al.2013). The $\bullet \mathrm{OH}$ Exposure increased from $0.04 * 10^{\wedge}-10$ to $1.4^{*} 10^{\wedge}-10$ for an increment of specific ozone dose of 0.5 to $1.5 \mathrm{gm} \mathrm{O}_{3} / \mathrm{gm}$ TOC. From the linear regression, it was possible to determine the threshold ozone dose. The intercept of the linear line represents the value of threshold ozone dose, for which little $\bullet \mathrm{OH}$ is formed from ozone consumption in wastewater effluent. [Lee et.al.2013] Fig.3B shows the $p$-CBA degradation at different specific ozone doses. The $p$-CBA degradation increased from 5 to $62 \%$, for an increase in specific ozone dose of 0.5 to $1.5 \mathrm{gm} \mathrm{O}_{3} / \mathrm{gm}$ TOC. As shown in fig. $1 \mathrm{~B}$, the $p$-CBA degradation increases from $2 \%$ at a specific ozone dose of 0.5 to $51 \%$ at a specific ozone dose of $1.5 \mathrm{gm} \mathrm{O}_{3} / \mathrm{gm}$ TOC. At higher ozone dose, decreased $p$-CBA concentration indicates that ozone dose is a significant factor influencing $\bullet \mathrm{OH}$ exposure. As mentioned in Table 2, Rct value increases about 2.74 times at the highest specific ozone dose when compared with the lowest specific ozone dose. Fig. 3C, shows the effect of specific ozone dose on the rate of $p$-CBA degradation. With an increase in specific ozone dose, the rate of $p$ - 
CBA degradation increases. When the specific ozone dose was increased from 0.5 to $1.5 \mathrm{gm}$ ozone/ gm TOC, the rate of $p$-CBA degradation was observed to increase from 0.002 to 0.022 $\min ^{-1}$ i.e. nearly 11 times increment in rate constant was observed. The increased specific ozone dose enhances the availability of ozone, which can be further decomposed in to $\bullet \mathrm{OH}$ and promotes $p$-CBA degradation.

Figure 3:(A) Effect of specific ozone dose on $\cdot$ OH exposure (B) Effect of specific ozone dose on $p$-CBA degradation (C) Effect of specific ozone dose on rate of $p$-CBA degradation

Table 2: Effect of specific ozone dose on Rct, ozone and .OH Exposure

\subsection{Effect of $\mathrm{pH}$ on the performance of catalytic ozonation}

The value $\mathrm{pH}$ plays a vital role in the decomposition of ozone in the aqueous system. In aqueous systems, the chain reaction transforms $\mathrm{O}_{3}$ into $\bullet \mathrm{OH}$. The $\mathrm{pH}$ can accelerate the initiation of the chain reaction. The role of initiator, promoters and inhibitors can be played by several compounds. (Staehelin and Hoigne,1985). The formation of $\bullet \mathrm{O}_{2}{ }^{-}$is due to the initiator. The promoters are attributed to the regeneration of $\bullet^{-}{ }^{-}$ions from hydroxyl radicals and the inhibitor compounds are capable of consuming hydroxyl radicals without regeneration of superoxide anions. The $p$-CBA degradation depends on ozone decomposition. Therefore, $p$-CBA degradation is an indirect measure of ozone decomposition. In the case of AC catalyzed ozonation, an increase in $\mathrm{pH}$ level from 5 to 9 , observed 25 to $60 \%$ increment in $p$-CBA degradation and $\bullet \mathrm{OH}$ exposure increased from $5.75^{*} 10^{\wedge}-11$ to $1.83^{*} 10^{\wedge}-10$ M.s as shown in Table 3 and fig 4A. The rate constant of $p$-CBA degradation increases from 0.008 to $0.030 \mathrm{~min}^{-1}$ depicted in fig. 4B. The MWCNT catalyzed shows a similar trend of an increment in pcba degradation with an increase in $\mathrm{pH}$ level. At $\mathrm{pH} 5,30 \% p$-CBA removal was observed and was increased to $70 \%$ at $9 \mathrm{pH}$ and the corresponding increase in $\cdot \mathrm{OH}$ exposure was from $7.13^{*} 10^{\wedge}-11$ to $2.40^{*} 10^{\wedge}-10$ M.s as shown in fig. $5 \mathrm{~A}$ and Table 4 . Fig.5B shows that, the rate constant for $p$-CBA degradation was increased nearly five times for $\mathrm{pH} 9$ when compared with $5 \mathrm{pH}\left(0.008\right.$ to $\left.0.041 \mathrm{~min}^{-1}\right)$. The Rct increment for AC catalyzed ozonation is nearly 29 times i.e. from $1.12^{*} 10^{\wedge}-8$ to $3.25^{*} 10^{\wedge}-7$ and in the case of MWCNT catalyzed ozonation, the increment was observed to be nearly 42 times at $9 \mathrm{pH}$ when compared $\mathrm{pH}$ level of 5 as shown in Table $3 \& 4$ respectively. The positive effect of increasing $\mathrm{pH}$ was also observed in the rate of ozone decomposition. Both the catalyst AC and MWNCTs have shown enhancement in ozone decomposition rate constant with increasing $\mathrm{pH}$. In the case of $\mathrm{AC}$, for a change in initial $\mathrm{pH}$ from 5 to 9 , the corresponding change in ozone decomposition rate is from 0.176 to $0.448 \mathrm{~min}^{-1}$. In the case of MWCNTs, for the same change in $\mathrm{pH}$, decomposition rate changes from 0.163 to $0.491 \mathrm{~min}^{-1}$ as shown in figures $4 \mathrm{C}$ and $5 \mathrm{C}$ respectively. Because there are more hydroxyl ions accessible under basic conditions for launching radical chain reactions, changes in $\mathrm{pH}$ can have a direct influence on liquid phase chain reactions. As a result, at higher $\mathrm{pH}$ levels, liquid phase reactions triggered by $\mathrm{OH}-\mathrm{may}$ account for the bulk of the produced hydroxyl radicals. 
Figure 4: Effect of $\mathrm{pH}$ on (A) $p$-CBA degradation of AC catalyzed ozonation (B) rate of p-CBA degradation of AC catalyzed ozonation (C) rate of ozone decomposition in $\mathrm{AC}$ catalyzed ozonation

\section{Table 3: Effect of pH on Rct, ozone and .OH Exposure in AC catalyzed ozonation}

Figure 5: Effect of pH on (A) p-CBA degradation of MWCNTs catalyzed ozonation (B) rate of ozone decomposition of MWCNTs catalyzed ozonation (C) rate of ozone decomposition of MWCNTs catalyzed ozonation

Table 4: Effect of pH on Ret, ozone and .OH Exposure in MWCNTs catalyzed ozonation

\subsection{Effect of catalyst loading}

The effect of AC and MWCNTs loading on $p$-CBA degradation is as shown in fig.6A \& $6 \mathrm{~B}$. The $\mathrm{pH}$ was maintained at 9. As the dose of AC increased from 50 to $100 \mathrm{mg}, p$-CBA degradation was observed to increase by $9 \%$ and further increment to $200 \mathrm{mg}$ had shown 12 $\%$ enhancement in $p$-CBA degradation when compared with 50mg dose as shown in fig.6A. The rate of $p$-CBA degradation was observed to increase with an increment in AC dose as depicted in fig 6C. With a fourfold increase in AC dose, i.e., from 50 to $200 \mathrm{mg}$, the rate of $p$ CBA degradation was observed to enhance by $1.47 \%$ times when compared with the $50 \mathrm{mg}$ dose. The ${ }^{\circ} \mathrm{OH}$ exposure also increases with an increase in AC dose. For increment of AC dose from 50 to $200 \mathrm{mg}$, the ${ }^{\bullet} \mathrm{OH}$ exposure increased from $1.83^{*} 10^{\wedge}-10$ to $2.54^{*} 10^{\wedge}-10$. The corresponding increase in Rct was observed from $3.25^{*} 10^{\wedge}-7$ to $1.51^{*} 10^{\wedge}-6$ as shown in the table 5 .

An increment in MWCNTs dose showed enhanced $p$-CBA degradation, increased ${ }^{\circ} \mathrm{OH}$ exposure and increased Rct. When MWCNTs dose was increased from 50 to $100 \mathrm{mg}, p$-CBA degradation was increased by $4 \%$ and further increment of MWCNTs dose to $200 \mathrm{mg}$ resulted in $10 \%$ enhancement in $p$-CBA degradation as shown in fig. $4 \mathrm{~B}$. The rate of $p$-CBA degradation was increased by 1.39 times, for increment of MWCNTs dose from 50 to $200 \mathrm{mg}$, when compared with the $50 \mathrm{mg}$ dose as shown in fig.4D. The ${ }^{\circ} \mathrm{OH}$ exposure was increased from $2.4^{*} 10^{\wedge}-10$ to $3.22 * 10^{\wedge}-10$ for an increment of 50 to $200 \mathrm{mg}$ and the corresponding increase in Rct was from $1.497 * 10-8$ to $6.42 * 10-7$ as shown in the table 6 .

The ozone decomposition follows pseudo first order kinetics. The rate of ozone decomposition increases with an increase in $\mathrm{AC}$ dose. When $\mathrm{AC}$ loading was increased from 50 to $100 \mathrm{mg}$, the corresponding increase in ozone decomposition rate constant was found to increase from 0.625 to $1.005 \mathrm{~min}^{-1}$ and further increase in AC dose to $200 \mathrm{mg}$ had shown an ozone decomposition rate of 1.354 min-1in fig.6E. An increase in MWCNTs dose has shown enhancement in ozone decomposition rate constant. For an increase in MWCNTs dose from 50 to $100 \mathrm{mg}$, the rate constant of ozone decomposition increases from 0.638 to $1.354 \mathrm{~min}^{-1}$. Further increment in MWCNTs loading to $200 \mathrm{mg}$, did not show any increment in ozone decomposition rate constant as illustrated in fig $4 \mathrm{~F}$. The positive effect of catalyst loading in 

the case of AC and MWCNTs was observed for $\%$ increment of $p$-CBA degradation, rate of $p$-CBA degradation and rate of ozone decomposition. The enhancement in ${ }^{\circ} \mathrm{OH}$ exposure and Rct was also observed with increasing dose of AC and MWCNTs. This is attributed to the fact that an increase in catalyst dose provides a greater number of surface active sites and facilitates decomposition of ozone molecules into hydroxyl radicals.

Figure 6: Effect of catalyst loading on(A) $p$-CBA degradation in AC catalyzed ozonation (B) $p$-CBA degradation of MWCNTs catalyzed ozonation (C) rate of $p$-CBA degradation in AC catalyzed ozonation (D) rate of $p$-CBA degradation in MWCNTs catalyzed ozonation (E) rate of ozone decomposition of in AC catalyzed ozonation (F) rate of ozone decomposition of in MWCNTs catalyzed ozonation

Table 5: Effect of catalyst loading on Ret, ozone and .OH Exposure in AC catalyzed ozonation

\subsection{Determination of rate constant for reaction of organic matter with hydroxyl radicals}

The competition kinetic method (Liu et al. 2019) was used to estimate the rate constant of reaction of organic matter with hydroxyl radicals, using $p$-CBA as a probe component and tbutanol as a competitive scavenger

The selected wastewater matrix ${ }^{\ddot{Y}} \mathrm{OH}$ scavenging $\left(k_{1}\right)$ was determined by the steadystate $\ddot{Y}^{\bullet} \mathrm{OH}$ concentration. The steady-state ${ }^{\ddot{Y}} \cdot \mathrm{OH}$ concentration followed equation 3 and 4 (Liu et. 2019):

$k=k_{O H, p C B A}\left[{ }^{\circ} \mathrm{OH}\right]_{\mathrm{ss}}$

$\left[{ }^{\circ} \mathrm{OH}\right]_{\mathrm{ss}}=\frac{\alpha_{O H}}{k_{a}}$

Where, is $p$-CBA apparent rate constant of degradation, is the selected wastewater matrix $\ddot{\mathrm{Y}}^{\bullet} \mathrm{OH}$ scavenging rate constant, is the $\ddot{\mathrm{Y}}^{\bullet} \mathrm{OH}$ formation rate. $\left[{ }^{\circ} \mathrm{OH}\right]_{\text {ss }}$ is the steady-state ${ }^{\circ} \mathrm{OH}$ concentration.

Substituting equation 4 into equation 3 and then inverting both sides' results in:

$$
\frac{1}{k}=\frac{k_{1}}{k_{O H, p C B A} \alpha_{O H}}
$$


295 In this study, the major ${ }^{\ddot{O}} \mathrm{OH}$ scavengers during ozone-based AOPs in the water matrix are

296 DOM (dissolved organic matters), nitrite $\left(\mathrm{NO}_{2}^{-}\right)$and carbonate/bicarbonate $\left(\mathrm{CO}_{3}{ }^{2-} / \mathrm{HCO}_{3}{ }^{-}\right)$.

297 Therefore, the selected wastewater matrix ${ }^{\ddot{Y}} \mathrm{OH}$ scavenging rate constant followed equation 5:

$$
\begin{aligned}
k_{a}=k_{O H, D O M}[ & D O M]+k_{O H, N O_{2}^{-}}\left[\mathrm{NO}_{2}^{-}\right]+k_{O H, \mathrm{CO}_{3}^{2-}}\left[\mathrm{CO}_{3}^{2-}\right] \\
& +k_{O H, H C O_{3}^{-}}\left[\mathrm{HCO}_{3}^{-}\right]+k_{O H, p C B A}[p C B A] \\
& +k_{O H, t-B u O H}[t-B u O H]
\end{aligned}
$$

298 And substituting equation 6 into equation 5 results in:

$$
\begin{aligned}
& \frac{1}{k} \\
& =[t-B u O H] \frac{k_{O H, t-B u O H}}{k_{O H, p C B A} \alpha_{O H}} \\
& +\frac{k_{O H, D O M}[D O M]+k_{O H, N O_{2}^{-}}\left[\mathrm{NO}_{2}^{-}\right]+k_{O H, C O_{3}^{2-}}\left[\mathrm{CO}_{3}^{2-}\right]+k_{O H, H C O_{3}^{-}}\left[\mathrm{HCO}_{3}^{-}\right]}{k_{O H, p C B A} \alpha_{O H}} \\
& +\frac{k_{O H, p C B A}[p C B A]}{k_{O H, p C B A} \alpha_{O H}}
\end{aligned}
$$

299 Furthermore, $p$-CBA abatement follows pseudo-first-order kinetics.

$$
\ln \frac{[p C B A]_{t}}{[p C B A]_{0}}=-k \times t
$$

Where, $[p C B A]_{t}$ and $[p C B A]_{0}$ are the concentration of $p$-CBA at time $t$ and zero. As such, $k$ can be determined by means of measurement of $p$-CBA concentration. By plotting $1 / k$ as a function of the $\mathrm{t}-\mathrm{BuOH}$ concentration resulting in $1 / k$ and the $\mathrm{t}-\mathrm{BuOH}$ concentration are first-order linear relationships (Fig.S1):

$$
\begin{aligned}
& \mathrm{Y}=\mathrm{A}[t-\mathrm{BuOH}]+B \\
& \mathrm{Y}=\frac{1}{k} \\
& \mathrm{~A}=\frac{k_{O H, t-B u O H}}{k_{O H, p C B A} \alpha_{O H}} \\
& \mathrm{~B} \\
& =\frac{k_{O H, D O M}[D O M]+k_{O H, N O_{2}^{-}}\left[\mathrm{NO}_{2}^{-}\right]+k_{O H, C O_{3}^{2-}}\left[\mathrm{CO}_{3}^{2-}\right]+k_{O H, H C O_{3}^{-}}\left[\mathrm{HCO}_{3}^{-}\right]}{k_{O H, p C B A} \alpha_{O H}} \\
& +\frac{k_{O H, p C B A}[p C B A]+k_{O H, H_{2} O_{2}}\left[\mathrm{H}_{2} \mathrm{O}_{2}\right]}{k_{O H, p C B A} \alpha_{O H}}
\end{aligned}
$$

Dividing equation 11 by equation 10 results in: 


$$
\begin{aligned}
k_{O H, \mathrm{DOM}}= & \frac{1}{[\mathrm{DOM}]}\left(\frac{B}{A} k_{\mathrm{OH}, t-\mathrm{BuOH}}-k_{O H, \mathrm{NO}_{2}^{-}}\left[\mathrm{NO}_{2}^{-}\right]\right. \\
& -k_{O H, \mathrm{CO}_{3}^{2-}}\left[\mathrm{CO}_{3}^{2-}\right]-k_{O H, \mathrm{HCO}_{3}^{-}}\left[\mathrm{HCO}_{3}^{-}\right] \\
& \left.-k_{O H, \mathrm{PCBA}}[\mathrm{pCBA}]\right)
\end{aligned}
$$

The wastewater effluent samples, which were used to determine the selected wastewater ${ }^{\ddot{Y}} \mathrm{OH}$ scavenging. The results on scavenging kinetics are shown in Fig.7. The results of slope A and intercept $\mathrm{B}$ were $2.3 \times 10^{6} \mathrm{~s}$ and $33.2 \times 10^{3} \mathrm{~s} \mathrm{M}^{-1}\left(\mathrm{R}^{2} \approx 0.987\right)$, respectively. Therefore, the total ${ }^{\ddot{Y}} \mathrm{OH}$ scavenging rate constant $1.6 \times 10^{4} \mathrm{~s}^{-1}$

Figure 7: Competition kinetics plot for determination of the ${ }^{\bullet} \mathrm{OH}$ scavenging rate constant

\subsection{Effect of AC and MWCNT catalyzed ozonation on TOC and COD removal}

The effect of AC and MWCNT on COD and TOC removal is as shown in the fig.8A\& 8B. The catalyst dose, $\mathrm{Ph}$ and ozone dose were optimized as earlier. The catalyst dose for $\mathrm{AC}$ was $200 \mathrm{mg} / \mathrm{L}$, for MWCNTs was $100 \mathrm{mg} / \mathrm{L}$, pH was maintained at 9 and the specific ozone dose was $1.2 \mathrm{gm}$ of ozone /gm of TOC. It can be inferred from fig. COD removal in the case of MWCNTs is comparatively higher than AC catalyzed ozonation. The TOC removal in the case of MWCNT catalyzed ozonation was observed to be higher when compared with AC catalyzed ozonation.

Figure 8: Effect of AC and MWCNT catalyzed ozonation on (A) COD removal (B) TOC removal

\section{Conclusions:}

In the catalytic ozonation of textile wastewater, two catalysts were used. Activated carbon was synthesized from agricultural waste and Multiwalled carbon nanotubes were synthesized from plastic waste. The minimum requirement of ozone dose to form hydroxyl radicals was found in terms of specific ozone dose. Hydroxyl radical exposure was found to be increasing with an increased specific ozone dose. The rate of $p$-CBA degradation was observed to increase with increase in specific ozone dose and Rct.

Increasing $\mathrm{pH}$ from 5 to 9 had shown significant enhancement in hydroxyl radical exposure, rate of $p$-CBA degradation, Rct and rate of ozone decomposition. This trend was observed in $\mathrm{AC}$ as well as MWCNT catalysed ozonation. The MWCNT catalyzed ozonation has shown superior performance when compared with AC catalysed ozonation.

With increase in catalyst loading, the remarkable increment in hydroxyl radical exposure, rate of $p$-CBA degradation, Rct and rate of ozone decomposition were observed. The impact of 
catalyst loading was found dominantly positive in case of MWCNT catalysed ozonation. The competition kinetic method was used to estimate the rate constant of reaction of organic matter with hydroxyl radicals, using $p$-CBA as a probe component and t-butanol as a competitive scavenger.

Author contribution: All the authors are responsible for the entire manuscript.

Funding: This study is not supported by any agency.

Data Availability: The datasets used and/or analysed during the current study are available from the corresponding author on reasonable request.

\section{Declarations:}

Ethics approval and consent to participate: All authors have approval and consent to participate.

\section{Consent for publication: Not applicable.}

Competing interests: The authors declare no competing interests.

\section{References}

1. Ahn Y, Oh H, Yoon Y, Kyu Park W, Seok Yang W, Kang J, Effect of graphene oxidation degree on the catalytic activity of graphene for ozone catalysis, Journal of Environmental Chemical Engineering, Volume 5, Issue 4, August 2017, Pages 38823894, doi.org/10.1016/j.jece.2017.07.038

2. Audenaert W.T.M., Vandierendonck D., Van Hulle S.W.H., Nopens I., Comparison of ozone and HO induced conversion of effluent organic matter (EfOM) using ozonation and UV/H2O2 treatment, Water Res. 47 (2013) 2387-2398, https://doi.org/ 10.1016/j.watres.2013.02.003.

3. Bader, H.; Hoigne, J. Determination of ozone in water by the indigo method. Water Res. 1981, 15, 449-456, doi.org/10.1016/0043-1354(81)90054-3

4. Bajad G. S., Tiwari S.K.,Vijayakumar R.P.(2015), Synthesis and characterization of CNTs using polypropylene waste as precursor Materials Science and Engineering B 194,68-77. doi.org/10.1016/j.mseb.2015.01.004

5. Bhusari A.,Mazumdar B.,Rathod A.,Khonde R., (2020), Kinetics of catalyzed esterification of acetic acid with n-butanol using carbonized agro waste., International Journal of Chemical Kinetics, Volume52, Issue7, July , Pages 450-462, doi.org/10.1002/kin.21361

6. Bielski B.H.J., Cabelli D.E.,. Arudi R.L, Ross A.B.,Reactivity of HO2/O2-radicals in aqueous solution, J. Phys. Chem. Ref. Data 14 (4) (1985) 1041-1100. https://doi.org/10.1063/1.555739 
7. Chelkowska, K., Grasso, D., Fabian, I., Gordon, G., 1992. Numerical simulations of aqueous ozone decomposition. Ozone Sci. Eng.143349 doi.org/10.1080/01919519208552316.

8. Chen J.W., Hui C., Keiler T., Smith G., Catalytic ozonation in aqueous systems, in: AIChE (Ed.), AIChE Symposium Series, AIChE, New York, pp. 206-212, (1977)

9. Chiang Y.C., Wu P.Y., Adsorption equilibrium of sulfur hexafluoride on multiwalled carbon nanotubes, J. Hazard. Mater. 178,729-738, (2010). doi.org/10.1016/j.jhazmat.2010.02.003

10. Elovitz, M.S., von Gunten, U., 1999. Hydroxyl radical/ozone ratios during ozonation processes. I. The Rct concept. Ozone Sci. Eng. 21, 239260,doi.org/10.1080/01919519908547239.

11. Fan Xiaolei, Restivo João, Órfão José J.M., Pereira Manuel Fernando R., Lapkin Alexei A., The role of multiwalled carbon nanotubes (MWCNTs) in the catalytic ozonation of atrazine, Chemical Engineering Journal 241,66-76, (2014). doi.org/10.1016/j.cej.2013.12.023

12. Fontanier V., Farines V., Albert J., Baig S., Molinier J., Oxidation of Organic Pollutants of Water to Mineralization by Catalytic Ozonation, Ozone Sci. Eng. 27,115-128, (2005) doi.org/10.1080/01919510590925239

13. Goncalves AG, Orfao J J M, Pereira M F R; Catalytic ozonation of bezafibrate promoted by carbon materials. Applied Catalysis B: Environment, 2013;140141(0):82-91, https://doi.org/10.1016/j.apcatb.2013.03.034

14. Goncalves AG,Orfao JJM, Pereira MFR; Catalytic ozonation of sulfamethaxazole in presence of carbon material: Catalytic performance and reaction pathways; J. Hazad. Mater; 2012239-240(0): 167-74, DOI: 10.1016/j.jhazmat.2012.08.057

15. Guo Y, Zhub S, Wanga B, Huanga J, Denga S, Yua G, Wanga Y, Modelling of emerging contaminant removal during heterogeneous catalytic ozonation using chemical kinetic approaches, Journal of Hazardous Materials 380 (2019) 120888, doi.org/10.1016/j.jhazmat.2019.120888

16. Guoa Y, Zhaoa E, Wangb J, Zhanga X, Huangc H, Yua G, Wang Y, Comparison of emerging contaminant abatement by conventional ozonation, catalytic ozonation, O3/H2O2 and electro-peroxone processes, Journal of Hazardous Materials 389 (2020) 121829, doi.org/10.1016/j.jhazmat.2019.121829.

17. GuoY, Wang H, Wang B, Deng S, Huang J, Yu G, Wang Y, Prediction of micropollutant abatement during homogeneous catalytic ozonation by a chemical kinetic model, Water Research $142 \quad$ (2018) 383e395, doi.org/10.1016/j.watres.2018.06.019

18. Hoigné J., Chemistry of aqueous ozone and transformation of pollutants by ozonation and advanced oxidation processes, in: J. Hrubec (Ed.), Quality and Treatment of Drinking Water II, Springer Berlin Heidelberg, Berlin, Heidelberg, 1998, pp. 83-141. 
19. Jans U., Hoigné J., Activated carbon and carbon black catalyzed transformation of aqueous ozone into OH-radicals, Ozone Sci. Eng. 20,67-90, (1998). doi.org/10.1080/01919519808547291

20. Job N, Sabatier F, Pirard J P, Leonard A.,Towards the production of carbon xerogels monoliths by optimizing convective drying conditions., Carbon 2006, 44(12):2534-42. doi.org/10.1016/j.carbon.2006.04.031

21. Kasprzyk-Hordern B. , Ziółek M. , Nawrocki J., Catalytic ozonation and methods of enhancing molecular ozone reactions in water treatment, Appl. Catal. B Environ. 46 (4) (2003) 639-669. DOI: 10.1016/S0926-3373(03)00326-6

22. Langlais B. , Reckhow D.A., Brink D.R. , Ozone in Water Treatment: Application and Engineering, AWWA Research Foundation and Lewis Publishers, 1991.

23. Langlais, B., Reckhow, D.A., Brink, D.R., 1999. Ozone in Water Treatment: Applications and Engineering. Lewis Publishers, Boca Raton, FL

24. Lee Y., Gerrity D., Lee M., Bogeat A.E, Salhi E., Gamage S., Trenholm R.A., Wert E.C., Snyder S.A., von Gunten U., Prediction of micropollutant elimination during ozonation of municipal wastewater effluents: use of kinetic and water specific information, Environ. Sci. Technol. 47 (2013) 5872-5881, https://doi.org/10. 1021/es400781r.

25. Lee Y., Gerrity D., Lee M., Bogeat A.E., Salhi E., Gamage S., Trenholm R.A., Wert E.C., Snyder S.A., von Gunten U., Prediction of micropollutant elimination during ozonation of municipal wastewater effluents: use of kinetic and water specific information, Environ. Sci. Technol. 47 (2013) 5872-5881, https://doi.org/10. 1021/es400781r.

26. Lee Y., Kovalova L., McArdell C.S., von Gunten U., Prediction of micropollutant elimination during ozonation of a hospital wastewater effluent, Water Res. 64 (2014) 134-148, https://doi.org/10.1016/j.watres.2014.06.027

27. Liu Z Q, Ma J, Cui Y H, Zhang B P, Effect of ozonation pretretment on the surface properties and catalytic activity of multiwalled carbon nanotube. Applied Catalysis $\mathrm{B}$ :Environment,2009, 92(3-4):301-6. doi.org/10.1016/j.apcatb.2009.08.007

28. Liu Z, YangY, Shao C, Ji Z, Wang Q, Wang S, Guo Y, Demeestere K, VanHulle S, Ozonation of trace organic compounds in different municipal and industrial wastewaters: Kinetic-based prediction of removal efficiency and ozone dose requirements, Chemical Engineering Journal,Volume 387, 1 May 2020, 123405, doi.org/10.1016/j.cej.2019.123405

29. Liu Z., Chys M., Yang Y., Demeestere K., and Van Hulle S., Oxidation of Trace Organic Contaminants (TrOCs) in Wastewater Effluent with Different Ozone-Based AOPs: Comparison of Ozone Exposure and $\bullet \mathrm{OH}$ Formation, Ind. Eng. Chem. Res. 2019, 58, 8896-8902, doi.org/10.1021/acs.iecr.9b00293

30. Rodr1 'guez A., Rosal R., Perdigon-Melon J.A., Mezcua M., Aguera A., Hernando M.D., Leto n P., Ferna 'ndez-Alba A.R., Garcı 'a-Calvo E., Ozone-based technologies 
in water and wastewater treatment, Handbook of Environmental Chemistry, vol. 5 Part S/2, Springer-Verlag, Berlin Heidelberg, Germany, pp. 127-175,(2008)

450

451

452

453

454

455

456

457

458

459

460

461

462

463

464

465

466

467

468

469

470

471

472

473

474

475

476

477

478

479

480

481

482

31. Rosenfeldt E.J., Linden K.G., The ROH,UV Concept to Characterize and the Model UV/H2O2 Process in Natural Waters, Environ. Sci. Technol. 41 (2007) 2548-2553. https://doi.org/10.1021/es062353p

32. Staehelin J., Hoigne J., Decomposition of ozone in water in the presence of organic solutes acting as promoters and inhibitors of radical chain reactions, Environ. Sci. Technol. 19 (12) (1985) 1206-1213 doi.org/10.1021/es00142a012

33. von Gunten, U., 2003. Ozonation of drinking water: part I: oxidation kinetics and product formation. Water Research, 37 (7), 1443e1467. DOI: 10.1016/S00431354(02)00457-8

34. Von Gunten, U.; Hoigne, J. Bromate formation during ozonation' of bromidecontaining waters: Interaction of ozone and hydroxyl radical reactions. Environ. Sci. Technol. 1994, 28, 1234-1242, doi: 10.1021/es00056a009

35. Von Sonntag C., Von Gunten U., Chemistry of Ozone in Water and Wastewater Treatment, IWA Publishing, 2012.

36. Wert, E. C.; Rosario-Ortiz, F. L.; Snyder, S. A. Effect of Ozone Exposure on the Oxidation of Trace Organic Contaminants in Wastewater. Water Res. 2009, 43 (4), 1005-1014. DOI: 10.1016/j.watres.2008.11.050

37. Yong, E.L. and Lin, Y.P., 2012. Incorporation of initiation, promotion and inhibition in the R-ct concept and its application in determining the initiation and inhibition capacities of natural water in ozonation. Water Research 439 46(6), 1990-1998. DOI: $10.1016 /$ j.watres.2012.01.025

38. Yu F., Ma J., Wu Y.Q.,Adsorption of toluene, ethylbenzene and m-xylene on multi-walled carbon nanotubes with different oxygen contents from aqueous solutions, J. Hazard. Mater. 192, 1370-1379, (2011). doi.org/10.1016/j.jhazmat.2011.06.048 
Figures

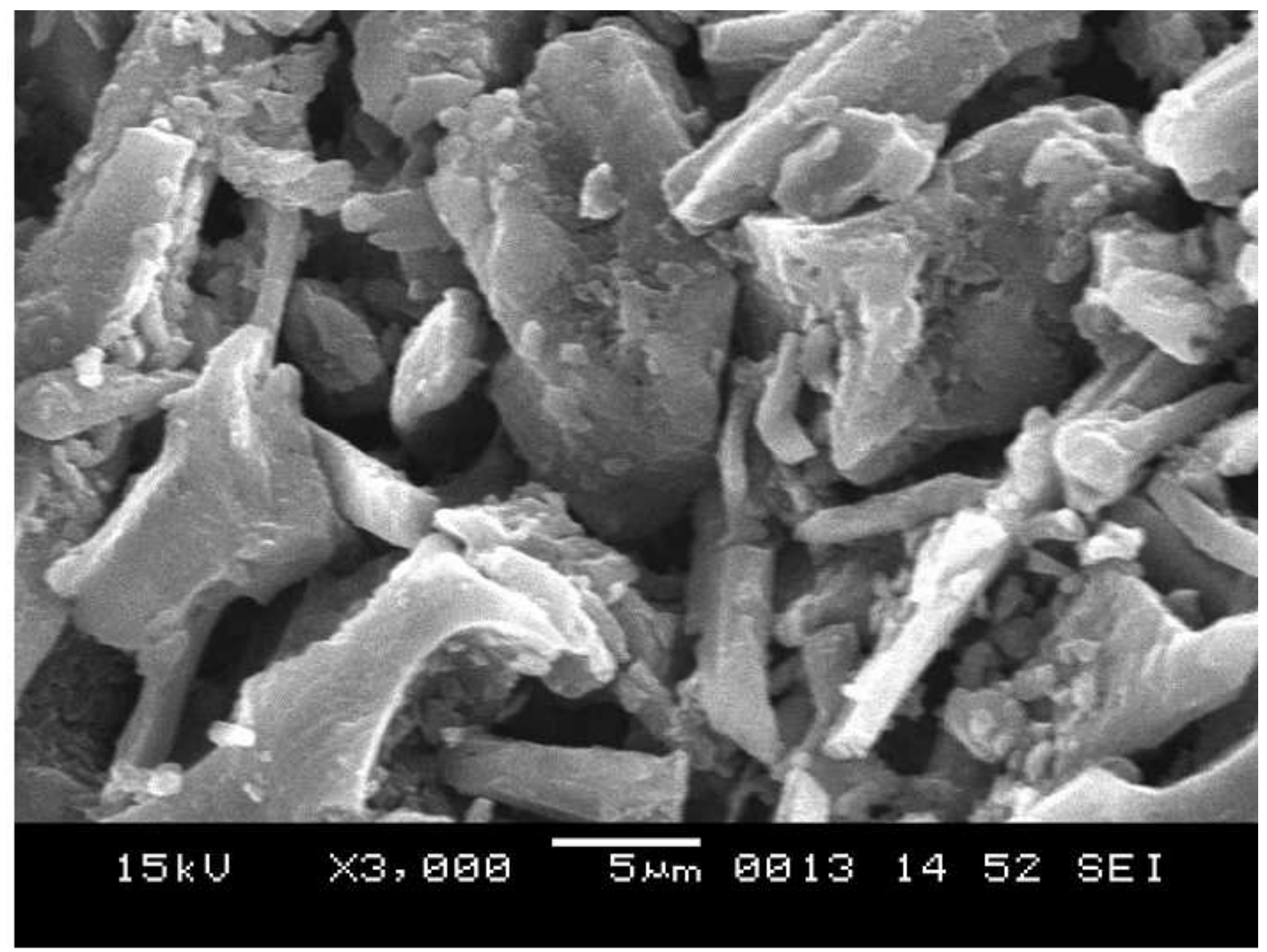

Figure 1

SEM image of Activated carbon 


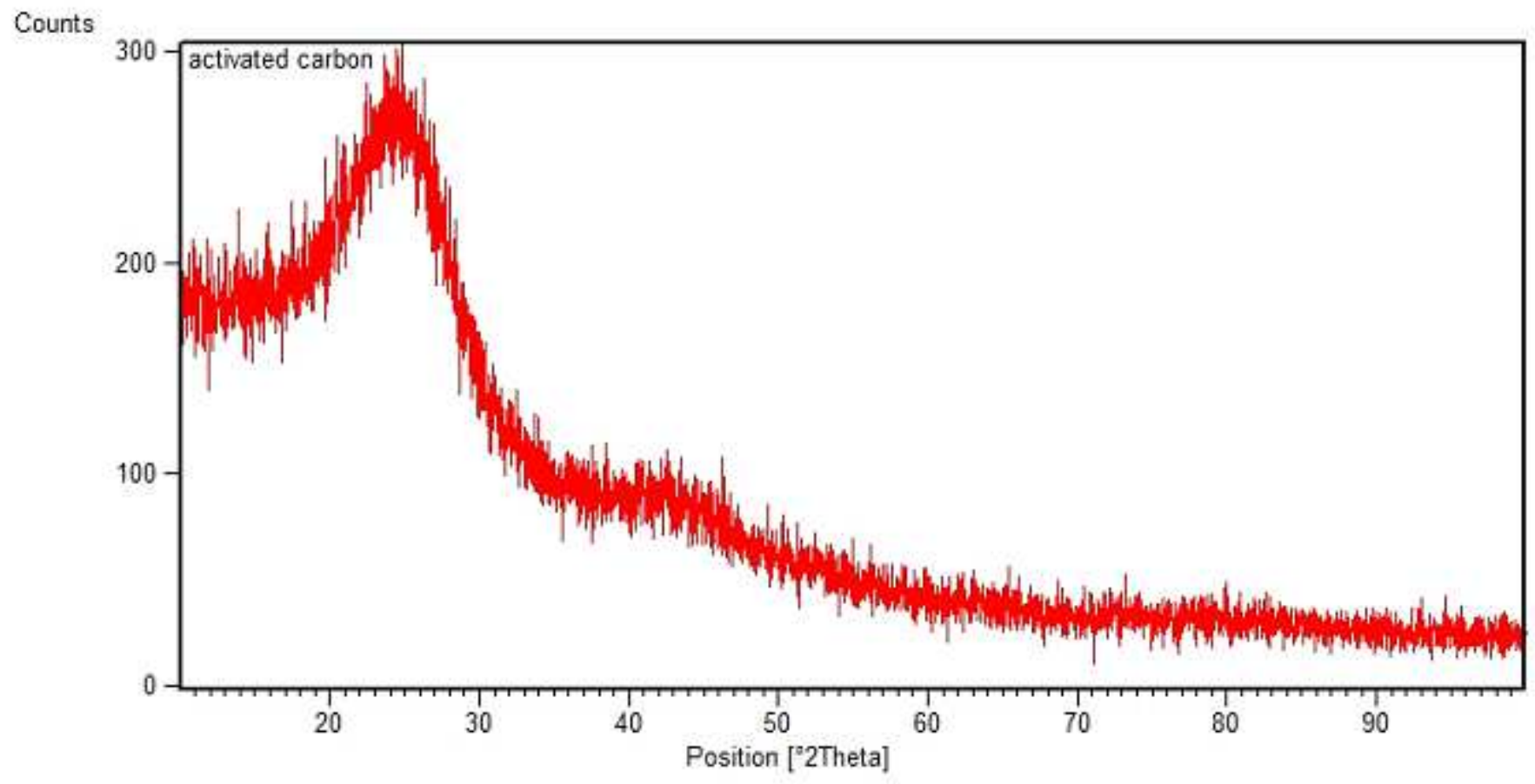

Figure 2

XRD Pattern for Activated Carbon 
A

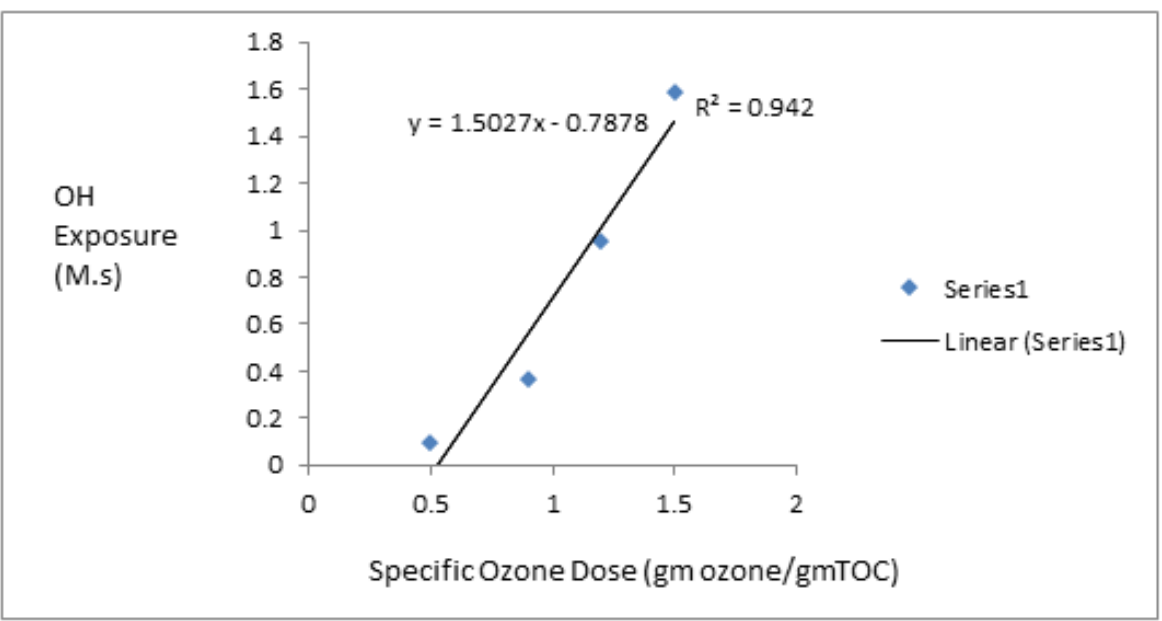

B

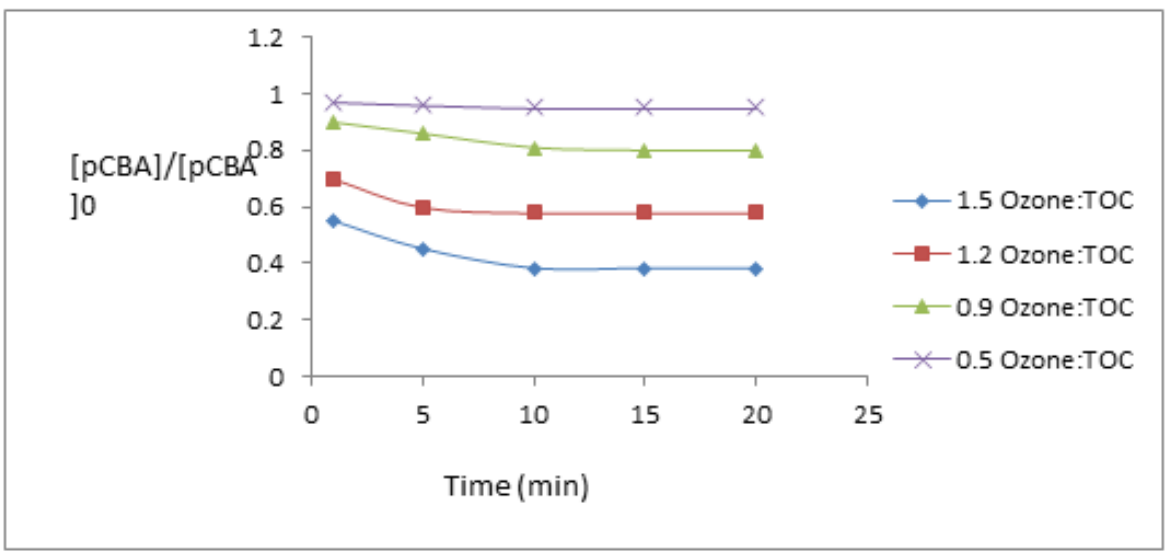

C

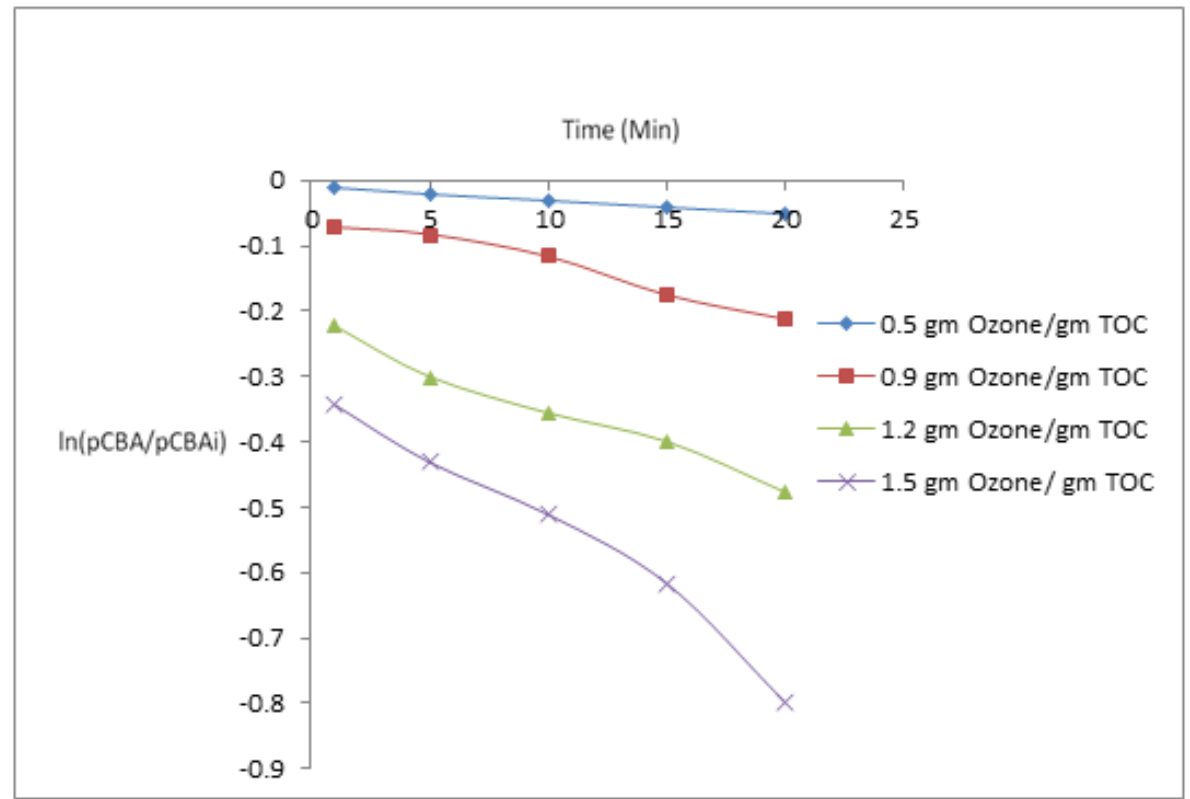

Figure 3

(A) Effect of specific ozone dose on $\cdot \mathrm{OH}$ exposure (B) Effect of specific ozone dose on p-CBA degradation (C) Effect of specific ozone dose on rate of p-CBA degradation 
A

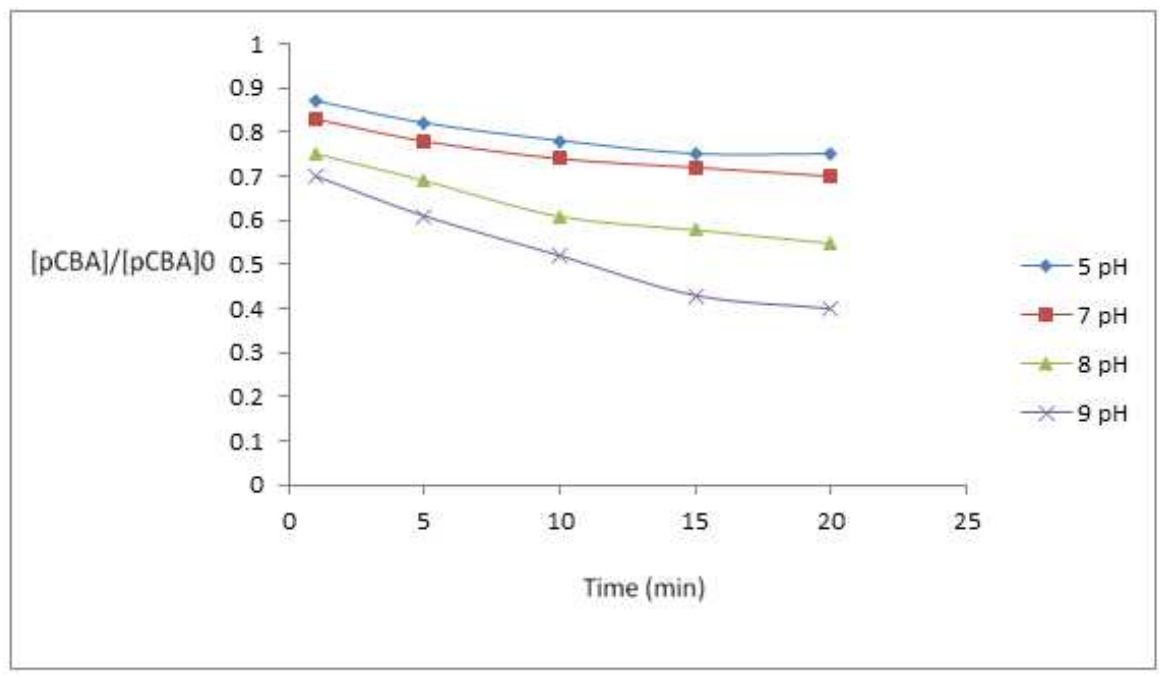

B

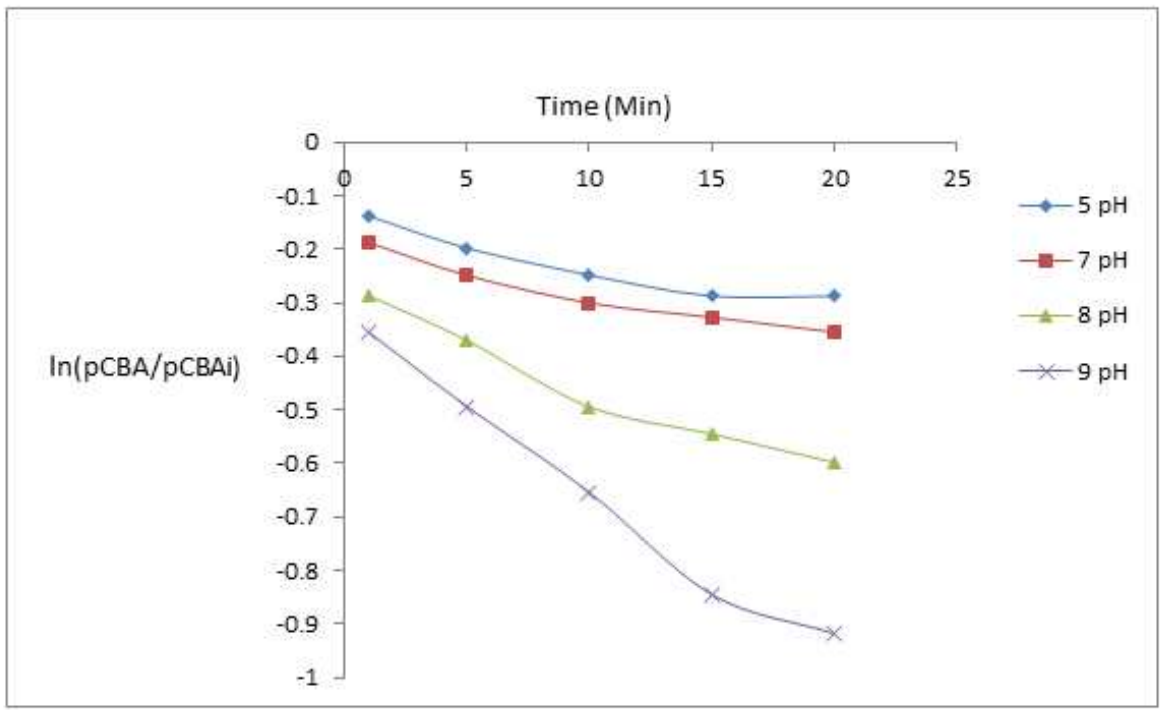

C

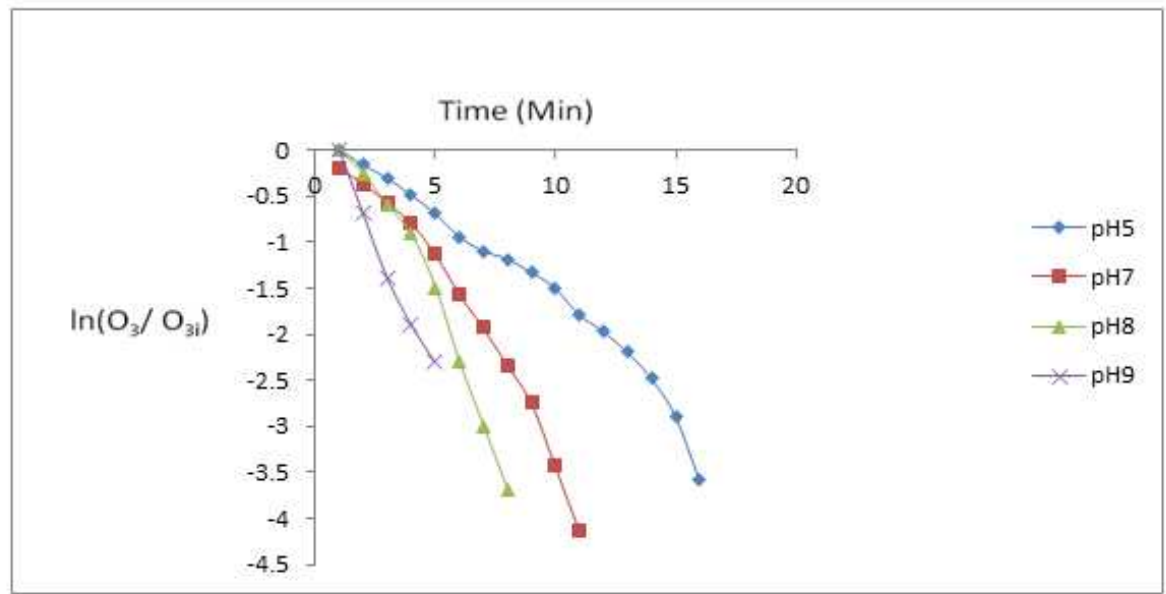

Figure 4

Effect of $\mathrm{pH}$ on (A) p-CBA degradation of $\mathrm{AC}$ catalyzed ozonation (B) rate of $\mathrm{p}$-CBA degradation of $\mathrm{AC}$ catalyzed ozonation $(C)$ rate of ozone decomposition in $A C$ catalyzed ozonation 
A

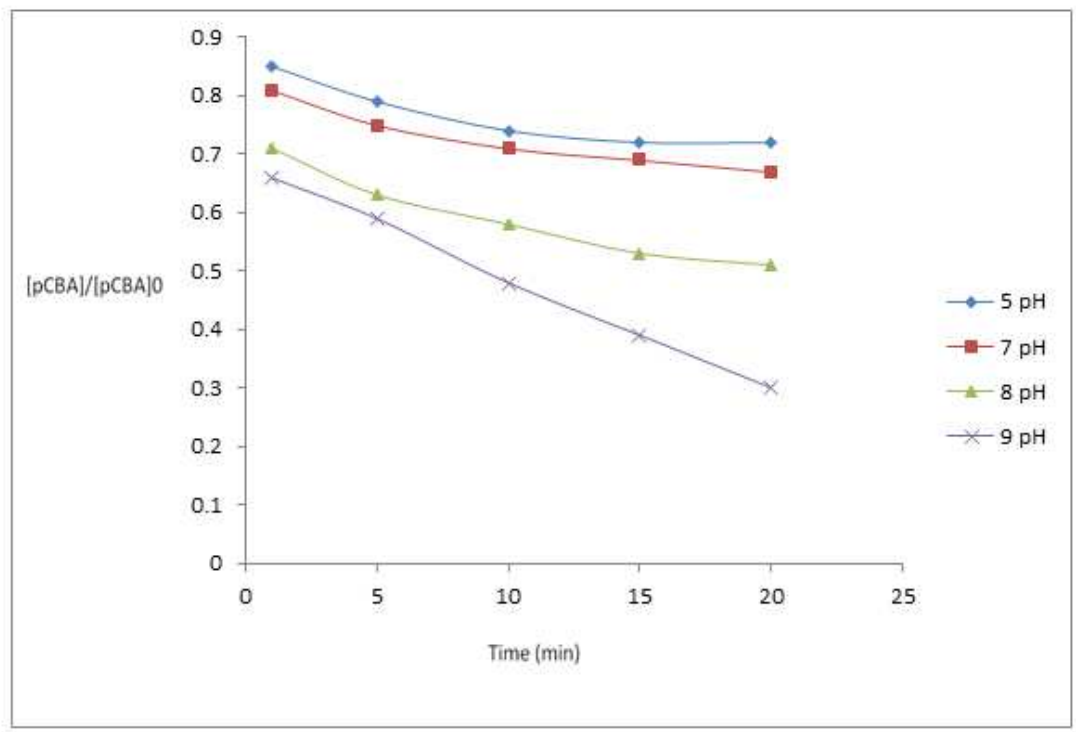

B

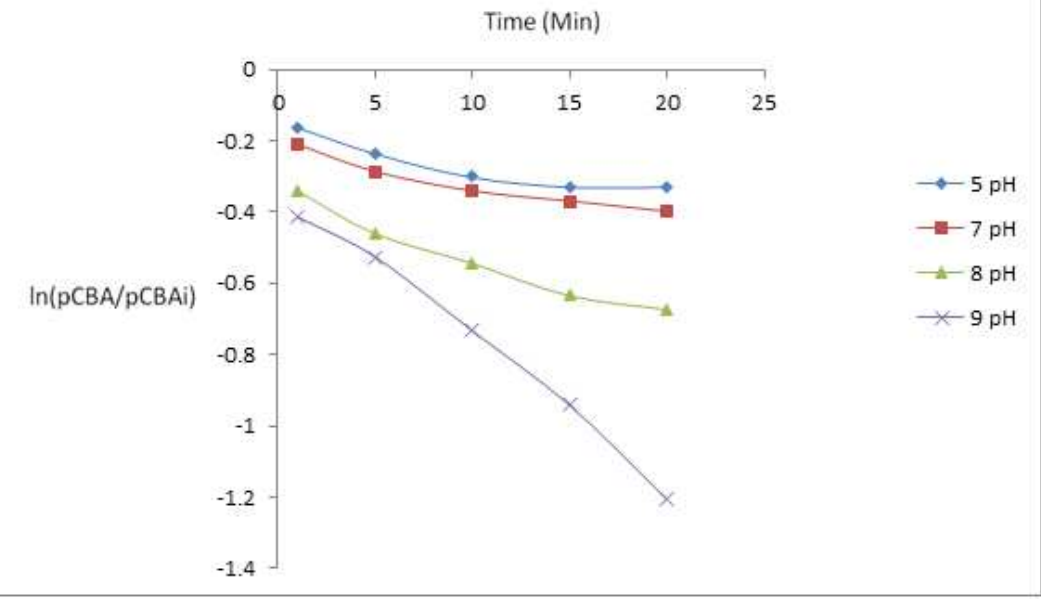

C

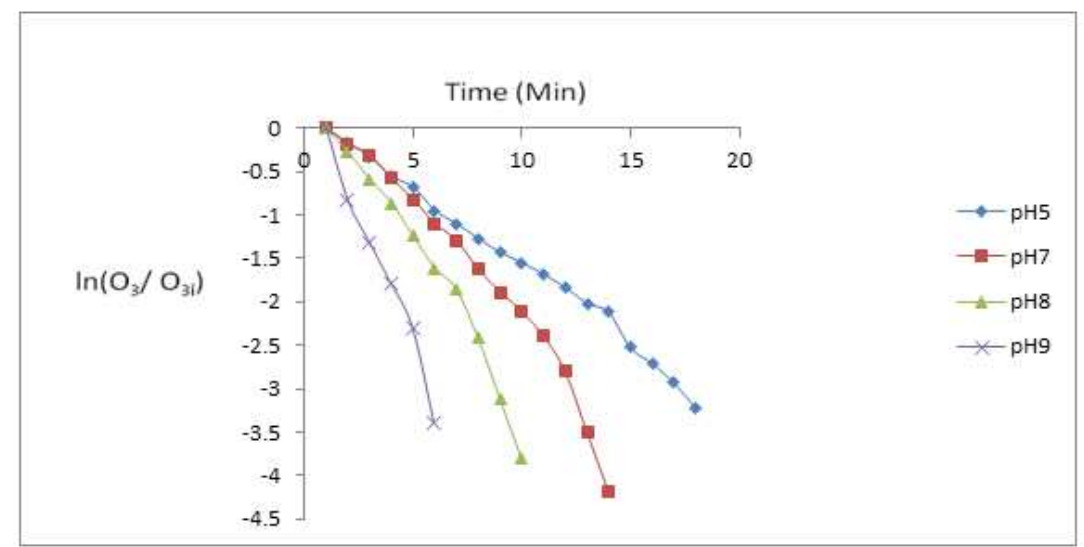

\section{Figure 5}

Effect of pH on (A) p-CBA degradation of MWCNTs catalyzed ozonation (B) rate of ozone decomposition of MWCNTs catalyzed ozonation (C) rate of ozone decomposition of MWCNTs catalyzed ozonation 
A

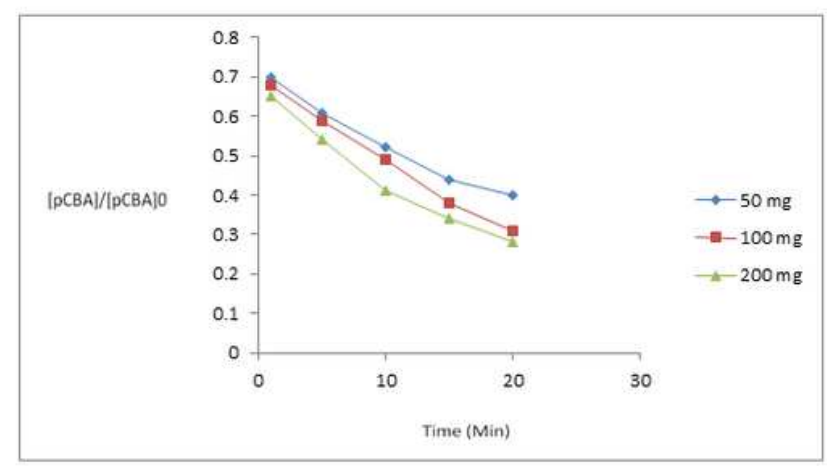

B

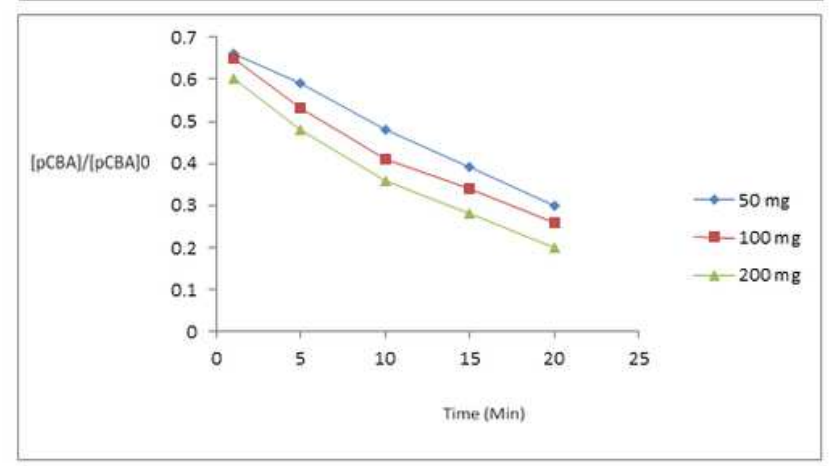

C

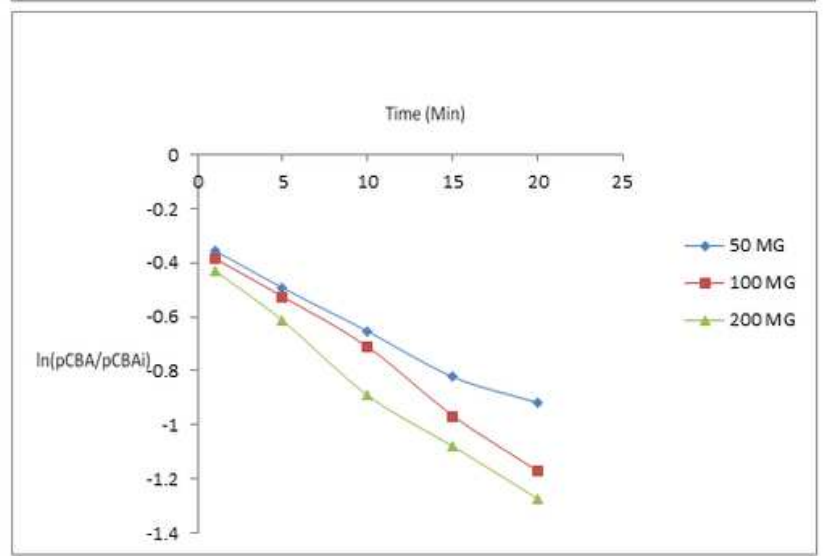

D

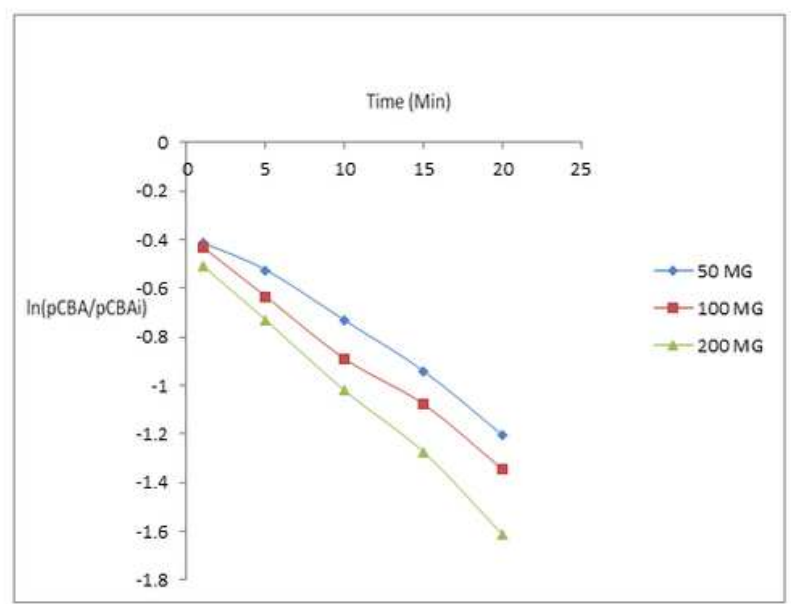

$\mathbf{E}$

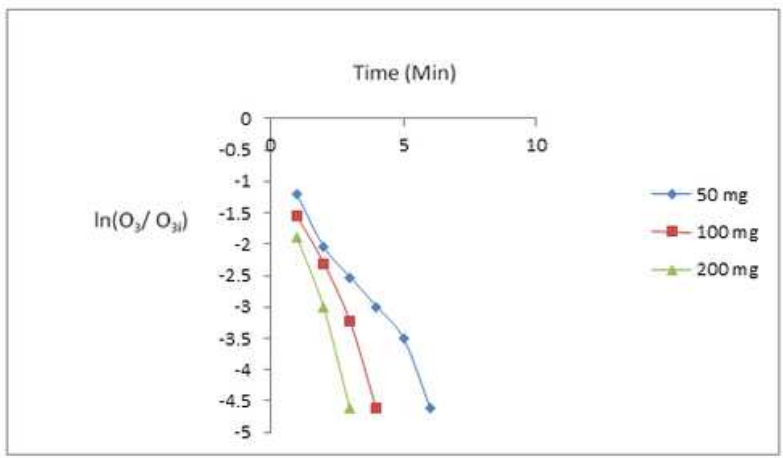

$\mathbf{F}$

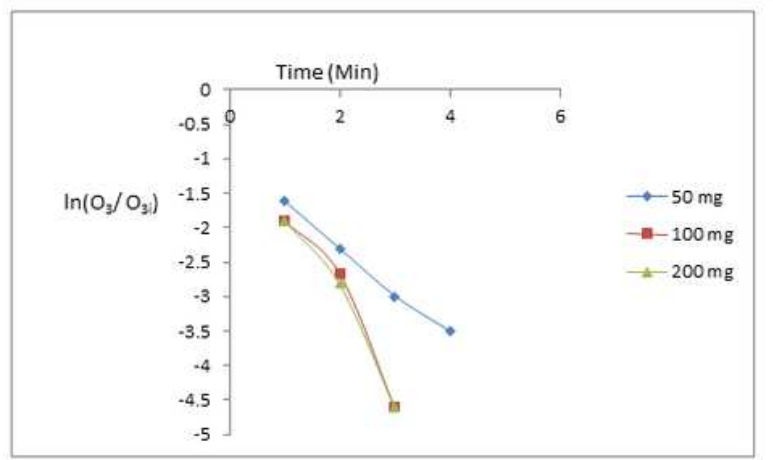

\section{Figure 6}

Effect of catalyst loading on(A) p-CBA degradation in AC catalyzed ozonation (B) p-CBA degradation of MWCNTs catalyzed ozonation (C) rate of $p$-CBA degradation in AC catalyzed ozonation (D) rate of $p$-CBA degradation in MWCNTs catalyzed ozonation (E) rate of ozone decomposition of in AC catalyzed ozonation (F) rate of ozone decomposition of in MWCNTs catalyzed ozonation 


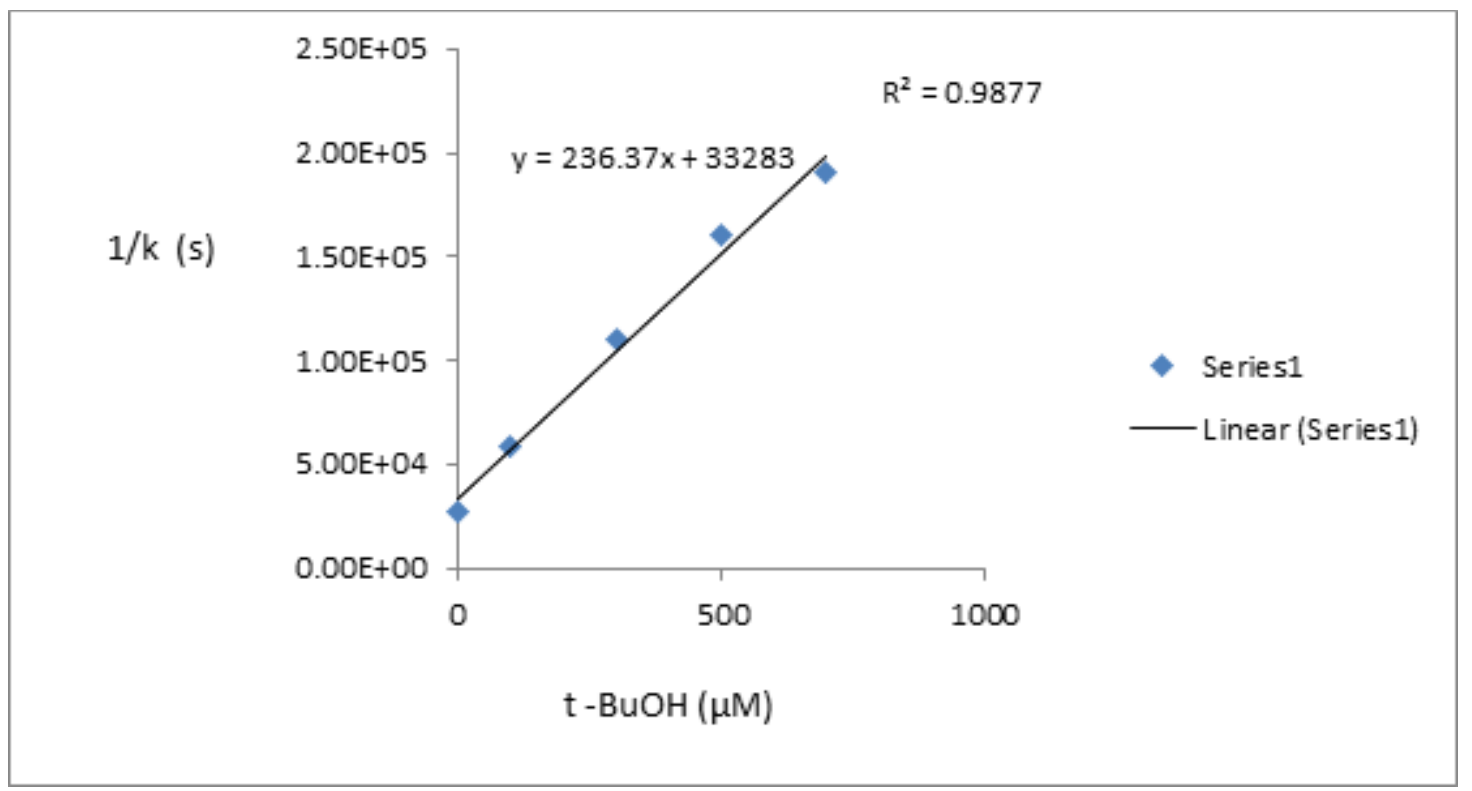

Figure 7

Competition kinetics plot for determination of the 'OH scavenging rate constant 
$\mathbf{A}$
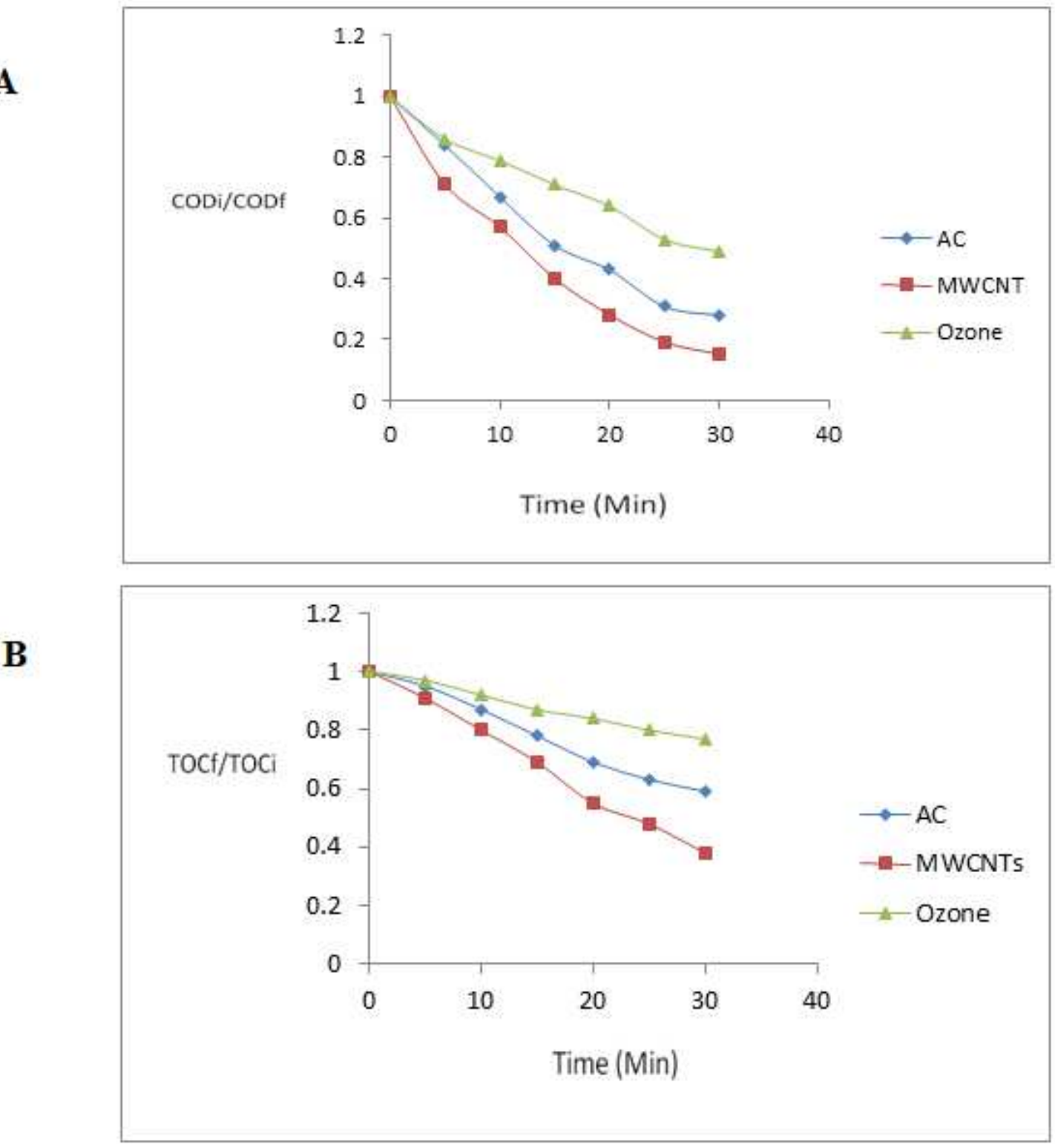

Figure 8

Effect of AC and MWCNT catalyzed ozonation on (A) COD removal (B) TOC removal

\section{Supplementary Files}

This is a list of supplementary files associated with this preprint. Click to download.

- GraphicalAbstract.docx 